\title{
Association of adult hippocampal neurogenesis with alzheimer's disease
}

\author{
Atrayee Gope*
}

Department of Applied Biosciences and Biotechnology, Imperial College London, England

Received: 02 November 2020

Accepted: 13 November 2020

\section{*Correspondence:}

Atrayee Gope,

E-mail: atrayee.gope@gmail.com

Copyright: $\odot$ the author(s), publisher and licensee Medip Academy. This is an open-access article distributed under the terms of the Creative Commons Attribution Non-Commercial License, which permits unrestricted non-commercial use, distribution, and reproduction in any medium, provided the original work is properly cited.

\section{ABSTRACT}

Neurogenesis in the adult brain has been reported to occur within three distinct regions, of which Hippocampus is the most studied one because of its importance in cognition and memory. Alzheimer's disease attributes to almost $62 \%$ of all dementia cases. A recent study has established a link between adult hippocampal neurogenesis and alzheimer's disease wherein a sharp decline in AHN is observed in patients suffering from alzheimer's. This review summarizes alzheimer's disease, the decline in AHN in alzheimer's patients and probes into the efficacy of the newly generated hippocampal neurons in the context of memory and cognition. It also discusses the potential of targeting reduced AHN in alzheimer's patients using neural stem cell-based therapy.

Keywords: Dementia, Alzheimer's disease, Neurogenesis, Adult hippocampal neurogenesis, Neural stem cells, Stem cell-based therapy

\section{INTRODUCTION}

Dementia is the decline in cognitive abilities such as memory, learning, language, etc., which hinders the normal day-to-day functioning of humans. ${ }^{1}$ It is more common in elderly people. The risk factor increases with ageing and by the age of 100 , dementia is almost inevitable. ${ }^{2}$ Most of the neurodegenerative diseases are usually sporadic, i.e., late onset diseases that are caused by a combination of various genetic and environmental factors. Alzheimer's disease is the most common form of dementia. $^{3}$ Some other forms of dementia include vascular dementia, mixed dementia, dementia with Lewy bodies, frontotemporal dementia, parkinson's disease, etc. Alzheimer's is a deadly neurodegenerative disease which occurs due to the loss of connectivity in the brain. The signs and symptoms of alzheimer's include memory impairment, slow decision-making, decline in language skills, increased depression, anxieties, phobias, anger, agitation, sleep problems, disrupted circadian rhythms, poor motor coordination. ${ }^{4-6}$ There are only five drugs approved to help the disease. ${ }^{7}$ Not much progress has been made since 2003 when the last drug was approved.
For most of the twentieth century, it was believed that adult neurons are fully differentiated and post-mitotic i.e. they lack the ability to divide. It was accepted that brain cells couldn't renew themselves post their development in embryonic and early postnatal life. ${ }^{8}$ Later on, there was evidence in favor of adult neurogenesis occurring in some specific parts of the brain i.e., within the sub granular layers the hippocampal dentate gyrus and in the subventricular zone of the olfactory bulb. ${ }^{9}$ In a recent study, it was reported that there is a decline in adult hippocampal neurogenesis (AHN) in patients suffering from alzheimer's disease.$^{10}$ Recent findings also suggest that stem cell-based therapies could possibly be used for treating certain neurodegenerative diseases like alzheimer's. ${ }^{11}$

\section{ALZHEIMER'S DISEASE: CAUSES AND TREATMENT}

Alzheimer's disease (AD) is characterized by the accumulation of extracellular amyloid plaques and intracellular neurofibrillary tangles, and brain atrophy (substantial loss of brain volume, enlarged ventricles, 
widened sulci, thinned gyri). ${ }^{12}$ The major component of amyloid plaques is the beta-amyloid peptide and the main component of neurofibrillary tangles is the microtubule stabilizing protein tau (hyperphosphorylated). The amyloid precursor protein (APP) is processed either by the amyloidogenic or the non-amyloidogenic pathway. ${ }^{13}$ APP processing by the amyloidogenic pathway results in the accumulation of the amyloid-beta protein into the extracellular space. Additionally, the hyperphosphorylation of tau under the control of genes such as MARK, CDK5 and GSK3 $\beta$ results in the destabilization of the microtubules and also affects axonal transport and neuronal function. ${ }^{14,15}$ There are two forms of AD to which genetic factors are attributed, early-onset or familial $\mathrm{AD}$ and late-onset or sporadic AD. Familial AD is rare, with only $5 \%$ of the Alzheimer's patient population suffering from it, while the rest $95 \%$ corresponds to sporadic AD. ${ }^{16}$ Familial AD is caused by mutation in the following three genes, amyloid precursor protein-APP, presenilin 1 and 2-PS1, PS2. On the other hand, sporadic AD is caused by a combination of genetic and environmental factors. The strongest genetic risk factor for sporadic $\mathrm{AD}$ is the apolipoprotein $\mathrm{E} \varepsilon 4$ (APOE $\varepsilon 4$ ) allele. ${ }^{17}$ APOE is a lifestyle protein involved in the catabolism of lipids and lipoproteins. ${ }^{18,19} \mathrm{AD}$ is incurable so the treatment focusses on reducing the symptoms and the progression of the disease. ${ }^{20}$ Some of the therapeutic strategies for treating AD target amyloidbeta accumulation (immunotherapy, metal chelators (clioquinol), BACE inhibitors (ATg-Z1) etc.), tau hyperphosphorylation/microtubule dysfunction (CDK5 inhibitors, GSK3 $\beta$ inhibitors etc.), acetylcholine signaling (acetylcholine inhibitors (donepezil, galantamine, taurine, rivastigmine), muscarinic receptor agonists(NGX267), etc.,) glutamate signaling (NMDA receptor antagonists, ampakines), other neurotransmitter receptors and ion channels (serotonin receptor antagonists, calcium channel blockers, etc.,), inflammation, oxidative stress, preventive measures (for e.g. cholesterol lowering agents; lovastatin, pravastatin), neuroprotective mechanisms (NGF gene therapy, neural stem cell therapy, etc.,). ${ }^{20}$ Apart from this, physical activity plays a major role in improving the overall function of the brain; it enhances neurogenesis and prevents cognitive decline thus delaying and lessening the symptoms of $\mathrm{AD} \cdot{ }^{21-23}$ There are fewer known targets of $\mathrm{AD}$ due to the lack of connectome data which further corresponds to fewer treatment opportunities.

\section{NEUROGENESIS IN THE ADULT BRAIN}

For a long time, it was believed that adult neurons do not regenerate. ${ }^{24}$ However, Joseph Altman, in 1962, found evidence of adult hippocampal neurogenesis in rodents. ${ }^{25}$ Later, Eriksson et al discovered the birth of new neurons in the adult brain. ${ }^{26}$ Adult neurogenesis has now been described within the sub-granular layer of the hippocampal dentate gyrus, in the subventricular zone of the olfactory bulb and in the amygdala. Evidence for the occurrence of adult neurogenesis in the amygdala was found later on. ${ }^{27,28}$ However, adult neurogenesis is quite controversial because the rate of neurogenesis declines after birth and also the function of the little number of new neurons generated is not clearly identified. Most research studies focus on adult hippocampal neurogenesis because hippocampus is the most likely region to contribute to a significant part of brain function. ${ }^{26,29}$ Adult hippocampal neurogenesis decreases with ageing, while physical exercise has a positive effect on the neurogenic capacity of the brain. ${ }^{26}$ The newly born neurons in the hippocampus may play some role in cognitive processes like memory, learning, regulation of mood, etc. but there is no direct evidence to back it up. ${ }^{30}$ Some studies have established a co-relation between dysregulated adult hippocampal neurogenesis and mental illness such as anxiety, depression etc. ${ }^{31,32}$ But these experiments are focused on rodent models and as a result, they don't necessarily give a clear picture of the scenario in humans.

\section{DECLINE OF ADULT HIPPOCAMPAL NEURO- GENESIS IN AD}

The hippocampus is severely affected in patients suffering from AD. ${ }^{33}$ Due to difficulties in conducting experiments on a human brain; there is a lack of insights on the integration of neutrons into the dentate gyrus of the hippocampus. While a majority of research studies in the past revealed a decrease in the number of new born hippocampal neurons in $\mathrm{AD}$, a few also claimed opposite results. ${ }^{34,35}$ A recent study used tightly controlled human brain samples to compare between adult hippocampal neurogenesis in a healthy brain to that in a diseased brain (Figure 1).

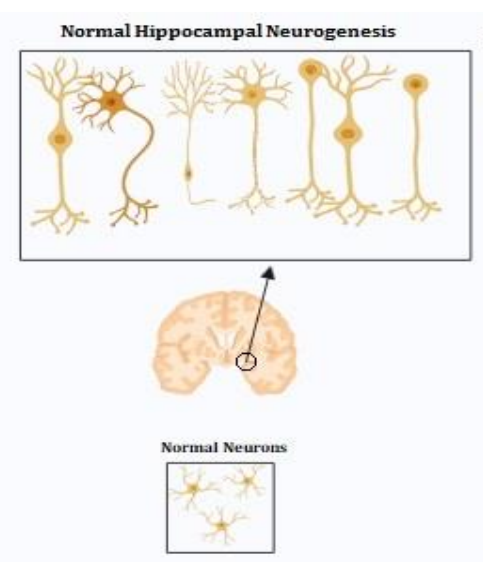

A

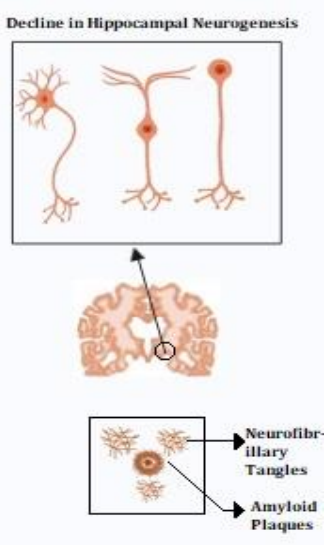

B
Figure 1: (A) A healthy brain (coronal cut, at basal ganglia). The healthy brain produces normal healthy neurons. Also, adult hippocampal neurogenesis takes place as usual in the healthy brain, (B) a diseased brain (affected by AD). AD is accompanied by the aggregation of neurofibrillary tangles and amyloid plaques as shown in figure. The brain also suffers from a dysfunctional adult hippocampal neurogenesis wherein there is a decline in the number of immature neurons in the hippocampus and their rate of maturation. 
It was found out that immature neutrons are integrated into the dentate gyrus of hippocampus which exhibits some level of maturation. On the other hand, in subjects with $\mathrm{AD}$, it was observed that as $\mathrm{AD}$ progressed, there was a characteristic decline in the number of immature neutrons and their rate of maturation. ${ }^{10}$ Although adult hippocampal neurogenesis declines with ageing, but the number and maturation of immature neurons within the dentate gyrus of hippocampus of healthy adults of any age are still higher than that of alzheimer's patients. ${ }^{10}$ This information opposes the idea that alzheimer's is caused due to ageing. Also, the decline in hippocampal neurogenesis is observed early in patients with AD and it, henceforth, can be used as a diagnostic tool for AD. ${ }^{36}$ Some researchers also have contrasting views to the aforementioned study and argue that the cells that were found within the hippocampus are nothing but mature neurons that have been present since birth. ${ }^{36}$

\section{TARGETING ADULT NEURAL STEM CELLS}

The occurrence of neural stem cells in the adult brain and persistence of adult neurogenesis opened up huge potential for stem-cell based therapy aimed at improving the condition of a diseased brain. ${ }^{37}$ But there are also multiple challenges that come in way of stem-cell based therapy, one important being the potential to develop tumors. ${ }^{37}$ Also, the newly formed neurons must integrate into the correct circuit or it could have detrimental effects. ${ }^{37}$ Embryonic stem cells, brain derived neural stem cells, mesenchymal stem cells and induced pluripotent stems cells are mostly used in AD research studies out of which mesenchymal stem cells are the most studied ones. $^{38-41}$

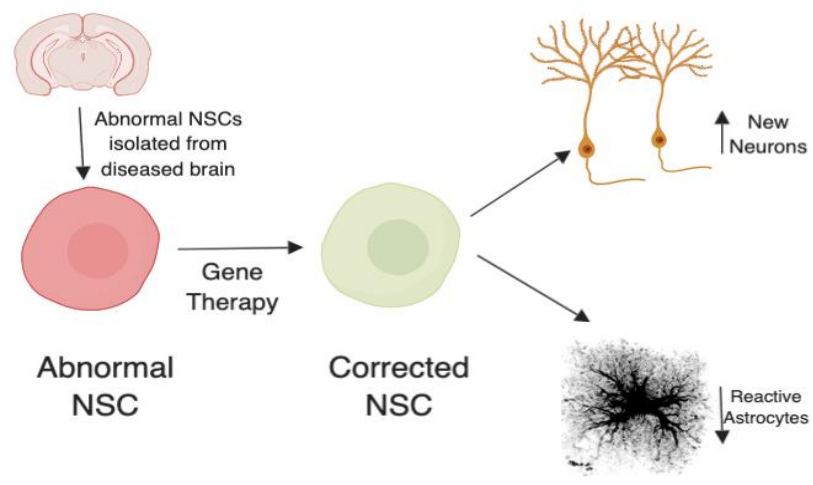

Figure 2: Abnormal neural stem cells can be isolated from the diseased brain. They can be then corrected by gene therapy. These corrected NSCs will produce more new healthy neurons and less reactive astrocytes. This method was used in alzheimer's mouse models to improve the conditions of the diseased brain. ${ }^{11}$

Modern strategies focus on correcting both Neural Stems and their niche. ${ }^{37}$ Adult neural stem cells mitigate several brain disorders like epilepsy, mental disorders, intellectual disability, etc. ${ }^{11} \mathrm{~A}$ recent study conducted on mouse models showed that enhanced hippocampal neurogenesis corresponded to the rescue of some diseased phenotypes. $^{42}$ However, inducing adult hippocampal neurogenesis alone can't improve the conditions of the diseased brain; it requires exercise induced improvement in cognition which is achieved by the over-expression of the brain derived neurotropic factor (BDNF). ${ }^{42}$ But this study clearly doesn't demonstrate the percentage of improvement in cognition. It could possibly be just a minor improvement which doesn't sound promising as far as the treatment of $\mathrm{AD}$ in human is concerned.

\section{CONCLUSION}

There have been recent advances in the field of $\mathrm{AD}$ especially in terms of its association with AHN. Given the sharp decrease in the number of neurons that is observed as AD progresses, correcting the neural stem cells and niche seems to be a potential therapy for treating alzheimer's. However, this area demands further research. Researchers should carry out a more extensive study to accurately determine the number of new-born neurons in the hippocampal circuit and compare it with the decline in alzheimer's patients to find out if there is a significant difference. It's quite skeptical to consider that the small numbers of newborn hippocampal neurons are sufficient to impact important brain functions such as memory, learning, cognition etc. The rarity of these new born neurons needs to be examined alongside the proper evaluation of their functions. Adult hippocampal neurogenesis declines with ageing or not is still a controversy. Some recent study claims that it continues even in old age. But, if this is not the case and AHN does decline during ageing, then researchers would need to concentrate on the earlier neurogenesis event that occurs during childhood and adolescence to see if this could help improve brain function. Additionally, the impact of improving hippocampal neurogenesis in AD mouse needs further research as to how strong the impact is or what is the percentage of improvement that is observed and if it's big enough to create an impact. Besides, most of the studies on animal models with successful results have been centered on rescuing familial AD phenotypes, which accounts only for about $5 \%$ of $\mathrm{AD}$ cases. The focus should be on sporadic AD instead. Human hippocampal neurogenesis needs to be studied in depth using various marker combinations. Addressing these questions would take some good amount of research and time but this arena holds the potential required to create a huge impact in the field of neurosciences.

Funding: No funding sources

Conflict of interest: None declared

Ethical approval: Not required

\section{REFERENCES}

1. Hugo J, Ganguli M. Dementia and cognitive impairment: epidemiology, diagnosis, and treatment. Clin Geriatr Med. 2014;30(3):421-42. 
2. Poon LW, Woodard JL, Stephen ML, Green R, Gearing M, Davey A, et al. Understanding dementia prevalence among centenarians. J Gerontol A Biol Sci Med Sci. 2012;67(4):358-65.

3. Qiu C, Fratiglioni L. Aging without dementia is achievable: current evidence from epidemiological research. J Alzheimers Dis. 2018;62(3):933-42.

4. Lanctôt KL, Amatniek J, Ancoli-Israel S, Arnold SE, Ballard C, Cohen-Mansfield J, et al. Neuropsychiatric signs and symptoms of Alzheimer's disease: New treatment paradigms. Alzheimers Dement Transl Res Clin Interv. 2017;3 (3):440-9.

5. Bature F, Guinn B, Pang D, Pappas Y. Signs and symptoms preceding the diagnosis of Alzheimer's disease: a systematic scoping review of literature from 1937 to 2016. BMJ Open. 2017;7(8):e015746.

6. Benoit M, Dygai I, Migneco O, Robert PH, Bertogliati C, Darcourt J, et al. Behavioral and Psychological symptoms in Alzheimer's Disease. Dement Geriatr Cogn Disord. 1999;10(6):511-7.

7. Zagorski N. Researchers continue to debate adult neurogenesis. Available at: https://doi.org/10.1176/ appi.pn.2018.5b8. Accessed on 20 August 2020.

8. Ming G-L, Song H. Adult neurogenesis in the mammalian brain: significant answers and significant questions. Neuron. 2011;70(4):687-702.

9. Moreno-Jiménez P, Flor-García M, Terreros-Roncal J, Rábano A, Cafini F, Pallas-Bazarra N, et al. Adult hippocampal neurogenesis is abundant in neurologically healthy subjects and drops sharply in patients with Alzheimer's disease. Available at: https://www.nature.com/articles/s41591-019-0375-9. Accessed on 20 August 2020.

10. Bao H, Song J. Treating brain disorders by targeting adult neural stem cells. Trends Mol Med. 2018; 24(12): 991-1006.

11. MacGill M. Alzheimer's disease: Symptoms, stages, causes, and treatment. Available at: https://www.medicalnewstoday.com/articles/159442. php. Accessed on 20 August 2020.

12. Robert E, Patrick K, Christian H, Christoph T, Kai S. Amyloidogenic processing of the Alzheimer $\beta$ amyloid precursor protein depends on lipid rafts . Available at: http://jcb.rupress.org/content/160/1/ 113.long. Accessed on 20 August 2020.

13. Boutajangout A, Sigurdsson EM, Krishnamurthy PK. Tau as a therapeutic target for alzheimer's disease. Curr Alzheimer Res. 2011;8(6):666-77.

14. Johnson GVW, Stoothoff WH. Tau phosphorylation in neuronal cell function and dysfunction. J Cell Sci. 2004;117(Pt 24):5721-9.

15. Types of alzheimer's disease. Available at: https://www.webmd.com/alzheimers/guide/alzheimer s-types. Accessed on 20 August 2020.

16. Corder EH, Saunders AM, Strittmatter WJ, Schmechel DE, Gaskell PC, Small GW, et al. Gene dose of apolipoprotein E type 4 allele and the risk of Alzheimer's disease in late onset families. Science. 1993;261(5123):921-3.
17. Dose J, Huebbe P, Nebel A, Rimbach G. APOE genotype and stress response - a mini review. Lipids Health Dis. 2016;15:121.

18. Mendiola-Precoma J, Berumen LC, Padilla K, Garcia-Alcocer G. Therapies for prevention and treatment of alzheimer's disease. Biomed Res Int. 2016;2016:2589276.

19. Maliszewska-Cyna E, Lynch M, Oore JJ, Nagy PM, Aubert I. The Benefits of exercise and metabolic interventions for the prevention and early treatment of alzheimer's disease. Curr Alzheimer Res. 2017;14 (1):47-60.

20. Chieffi S, Messina G, Villano I, Messina A, Esposito $\mathrm{M}$, Monda $\mathrm{V}$, et al. Exercise influence on hippocampal function: possible involvement of Orexin-A. Front. Physiol. 2017;8:85.

21. Ma C-L, Ma X-T, Wang J-J, Liu H, Chen Y-F, Yang Y. Physical exercise induces hippocampal neurogenesis and prevents cognitive decline. Behav Brain Res. 2017;317:332-9.

22. Jessberger $\mathrm{S}$. Neural repair in the adult brain. Faculty Rev. 2016;5:F1000.

23. Lois C, Kelsch W. Adult neurogenesis and its promise as a hope for brain repair. Front Neurosci. 2014;8:165.

24. Pedro B, José PA. Adult hippocampal neurogenesis: regulation and possible functional and clinical correlates. Front. Neuroanat.2018;52(8):213-9.

25. Bernier PJ, Bédard A, Vinet J, Lévesque M, Parent A. Newly generated neurons in the amygdala and adjoining cortex of adult primates. Proc Natl Acad Sci. 2002;99(17):11464-9.

26. Fowler CD, Liu Y, Wang Z. Estrogen and adult neurogenesis in the amygdala and hypothalamus. Brain Res Rev. 2008;57(2):342-51.

27. Anand KS, Dhikav V. Hippocampus in health and disease: An overview. Ann Indian Acad Neurol. 2012;15(4):239-46.

28. Toda T, Parylak SL, Linker SB. The role of adult hippocampal neurogenesis in brain health and diseases. Mol Psychiatry. 2019;24:67-87.

29. Schoenfeld TJ, Cameron HA. Adult neurogenesis and mental illness. Neuropsychopharmacol. 2015;40 (1):113-28.

30. Yun S, Reynolds RP, Masiulis I, Eisch AJ. Reevaluating the link between neuropsychiatric disorders and dysregulated adult neurogenesis. Nat Med. 2016;22(11):1239-47.

31. Steiner E, Tata M, Frisén JA. Fresh look at adult neurogenesis. Nat Med. 2019;25:542-3.

32. Peng L, Bonaguidi MA. Function and dysfunction of adult hippocampal neurogenesis in regeneration and disease. Am J Pathol. 2018;188(1):23-8.

33. $\mathrm{Mu} \mathrm{Y,} \mathrm{Gage} \mathrm{FH.} \mathrm{Adult} \mathrm{hippocampal} \mathrm{neurogenesis}$ and its role in Alzheimer's disease. Mol Neurodegener. 2011;6:85.

34. More evidence that humans do appear to create new neurons in old age. Available at: https://www.thescientist.com/news-opinion/more-evidence-that- 
humans-do-appear-to-create-new-neurons-in-oldage-65650. Accessed on 20 August 2020.

35. Jessberger S. Stem cell-mediated regeneration of the adult brain. Transfus Med Hemother. 2016;43(5): 321-6.

36. Duncan T, Valenzuela M. Alzheimer's disease, dementia, and stem cell therapy. Stem Cell Res Ther. 2017;8(1):111.

37. Bali P, Lahiri DK, Banik A, Nehru B, Anand A. Potential for stem cells therapy in alzheimer's disease: do neurotrophic factors play critical role? Curr Alzheimer Res. 2017;14(2):208-20.

38. Kwak K-A, Lee S-P, Yang J-Y, Park Y-S. Current perspectives regarding stem cell-based therapy for alzheimer's disease. Stem Cells Int. 2018; 2018: 6392986.

39. Choi SH, Bylykbashi E, Chatila ZK, Lee SW, Pulli B, Clemenson GD, et al. Combined adult neurogenesis and BDNF mimic exercise effects on cognition in an Alzheimer's mouse model. Science. 2018;361(6406):eaan8821.

40. Bergmann O, Spalding KL, Frisén J. Adult Neurogenesis in Humans. Cold Spring Harb Perspect Biol. 2015;7(7):a018994.

41. Duncan T, Valenzuela M. Alzheimer's disease, dementia, and stem cell therapy. Stem Cell Res Ther. 2017;8(1):111.

42. Gandhi S, Gupta J, Tripathi PP. The curious case of human hippocampal neurogenesis. ACS Chem Neurosci. 2019;10(3):1131-2.

Cite this article as: Gope A. Association of adult hippocampal neurogenesis with alzheimer's disease. Int J Community Med Public Health 2020;7:5208-12. 